\title{
To Investigate the Relationship between Reading Habits and Second Language Proficiency of EFL Students: A Classroom Study
}

\author{
Anjum Chaudhary \\ Assistant Professor \\ English Language Centre \\ Umm al-Qura University \\ Makkah, KSA
}

\begin{abstract}
The present study aims to explore the reading habits in native language and target language and also investigates the relationship between the reading habits and the L2 proficiency level of EFL students. For collecting data, a triangulated approach is used through a questionnaire, semi-structured interviews and class observations and to investigate the relationship between the reading habits and L2 proficiency level, the cumulative percentage of scores of formative and summative assessments are used. The findings show that there isn't any substantial relationship between the reading habits of learners in $L 1$ and $L 2$ and the second language proficiency.
\end{abstract}

Keywords: reading habits, native language, target language, second language proficiency, EFL students

\section{1-Introduction}

The literature on the reading skill efficiency of Saudi EFL learners indicates that Saudi students are reluctant readers in general. The reasons observed behind this disinclined reading attitude of Saudi students may be varied. This tendency is not limited to reading in English. Even reading in the Arabic language is not popular among the Saudi community which counts as a reason that students are not active readers in English too (Al-Nujaidi,2003). Lack of support from parents and teachers, monotonous reading materials and the learning environment are some of the factors held responsible for the reading difficulties which may be the reasons for Saudi EFL students to lose interest in reading in English (Mohammed, Q. \& Rashid, R.A, 2019). Teaching methodologies and content such as comprehension activities and strategies related to reading skills are very often being ignored in EFL classrooms (Al Nifayee,2010), consequently L2 learners have low reading ability. The above-mentioned views need to be addressed by the teachers to inculcate good reading habits among the language learners so that students change their negative attitude towards L2 reading and realize its importance as it contributes in achieving their goals by making them better readers, scoring high grades in exams and other educational and professional endeavours.

\subsection{Research Objectives}

a) To explore the reading habits of EFL students in L1 and L2.

b) To find the relationship between the reading habits of EFL students and second language proficiency.

\subsection{Research Questions}

a) What are the reading habits of EFL students in L1 and L2?

b) What is the relationship between second language proficiency and L1 and L2 reading habits of EFL Students?

\subsection{Significance of the study}

The present study gives an insight into the reading habits of EFL students and also helps to explore the relationship between reading habits and L2 proficiency. The findings may help the teacher to establish the main reasons behind learners' reluctance to read English and also to understand the levels and interests of the learners in reading. Furthermore, it helps to formulate methods to make them more engaged readers and enhance learners' participation in reading activities with more enthusiasm. Undoubtedly, English reading proficiency cannot be overlooked as it is vital for our students since they are being prepared for the future job market, thus, the issue motivated the researcher to investigate the present situation. With the purpose to motivate adult EFL learners to become good readers, the teacher conducted this research.

\section{2- Literature Review}

\subsection{Reading and its importance in Second Language Learning}


In simple words, reading is a process to get meaning out of a written text. It is one of those receptive skills in which learners infer information from a piece of reading. Many linguists consider reading skills as complex skills as they contribute to the other skills of language learning. For example, speaking skills also get enhanced as they are simultaneously used to pronounce the words in a reading text. Also, the role of a reader's personal notions, prior knowledge, and expectations in the process of comprehending a text cannot be neglected. Goodman (1994: 260) rightly posits, "Reading is a selective process. It involves partial use of available minimal language cues selected from perceptual input on the basis of the reader's expectation. As this partial information is processed, tentative decisions are made to be confirmed, rejected or refined as the reading progresses."

According to Nunan (1991:70) "Reading is a dynamic process in which the text elements interact with other factors outside the text, in this case, most particularly with the reader's knowledge of the content of the text". So, to better understand the meaning of the text, a reader not only uses a combination of reading skills, but other factors like, schemata, prior beliefs, etc. also play important roles in the process.

Hammerberg (2004) defines reading as a process of decoding words and also an interactive process that involves the active construction of meaning. For EFL/ESL learners, reading skills are very crucial as they help in building vocabulary, improving grammar and also writing. Thus, good reading habits are essential to developing foreign language (FL) proficiency. Good reading habits can be inculcated through extensive pleasure reading which is advocated by Richards and Schmidt (2002, 193-194), who state "extensive reading means reading in quantity and in order to gain a general understanding of what is read........is intended to develop good reading habits, to build up knowledge of vocabulary and structure, and to encourage a liking for reading". Extensive reading also leads to the gradual improvement of other language skills, such as writing style, vocabulary, grammar competence, and spelling skills (Krashen, 2004). Hence, many studies have proved that extensive reading is very helpful in developing language literacy in various domain.

\subsection{Relationship between $\mathrm{L1}$ and $\mathrm{L} 2$}

Several studies have been done on the relationship between L1 and L2 reading. Among all the theories, the two widely referenced hypotheses are - the linguistic interdependence hypothesis and the linguistic threshold hypothesis. Jim Cummins (1978) has proposed the linguistic interdependence hypothesis which advocates a notion that the skills of L1 are automatically transferred to the L2 learning process. Clarke (1980) has propounded the short circuit hypothesis, also known as the linguistic threshold hypothesis. It states that limited L2 language proficiency can restrict the transfer of L1 reading skills to L2 because L2 language proficiency has not reached the threshold level at which the transfer begins to occur.

Research by Alderson (1984) and Carrell (1991) examines the same issue and supports the above-mentioned theories. Therefore, it has been proved time and again that there is an essential relationship between L1 and L2 reading skills.

\subsection{Previous studies on reading skills and L2 proficiency}

Various researches have been conducted on different aspects of reading skills in L1 as well as L2. Some of them which seem important for the present study are mentioned below:

Mourtaga (2004) observes Arabic learners and concludes that learning to read English for them is challenging and poses difficulties due to poor vocabulary, low knowledge of grammar and syntax. Further, he suggests taking remedial measures to overcome these issues.

Hao and Chi (2013) study the positive role of L1 in second language acquisition (SLA). They examine several studies to prove their point that L1 should not be considered as an obstacle (interlingual interference), rather it has numerous positive impacts on L2 acquisition.

Gi- Pyo Park (2013) investigates relations among L1, L2 knowledge, and L2 reading under the scanner of the threshold hypothesis by Clarke (1980). In this comprehensive study, the researcher uses a sample of 2666 (1333 males and 1333 females) Korean EFL high school students. The findings show that L1 reading and L2 knowledge has a significant contribution to $\mathrm{L} 2$ reading comprehension.

$\mathrm{Li}$ (2014) studies the impact of reading strategies between the SA (studied abroad) and AH (at home) students across three different language proficiency levels. He concludes that the SA context was beneficial for intermediate learners on both language proficiency and reading comprehension skill improvement. For advanced level, it helped improving overall language proficiency, but not in reading whereas, on beginners, there seemed a threshold effect in both general skills and in reading skills.

The effects of reading on the development of skills in a second language were examined by Kelly Ise (2014). She reviews several types of research to know the effects of reading in L2 on adult learners' SLA. These effects can be either positive or negative. 
The aspects of reading, involved in SLA, are examined and findings show that learners' L1, learners' preference for strategies, perception towards text material and genre of text are considered important variables in SLA.

Furthermore, some findings show that good reading habits are developed during childhood. A study by Tarulli (2016) supports this notion and concludes that readers form a positive relationship with reading before the age of 15 . On the contrary, a research has confirmed that extensive reading can also result in good adult reading habits as shown by researchers like Smith (2013) who maintains that there is a positive relationship between extensive reading and literacy skills. Rodrigo et al. (2014) report the benefits of extensive reading interventions in the adult population. Thus, the literature review is in line with the aim of the present study that intends to explore the habits of adult EFL learners in L1(Arabic language) and the target language (English language), and also to find the relationship between these reading habits and overall second language proficiency.

\section{3- Methodology}

This section deals with the research methodology used in this study. It includes the research design, sample of the research, research tools, research procedures, and data analysis.

\subsection{Research Design}

A mixed-method approach was used in the current study which employed the qualitative as well as thequantitative approach. Three qualitative methods i.e. a questionnaire, semi-structured interviews and field notes from class observations were used to examine the reading habits of EFL learners in L1 and L2, whereas a quantitative method was used to calculate the percentage of the scores of students.

\subsection{Participants}

For the present classroom study, it was decided to use non-probability samples, thus, convenience sampling of two intact classes allotted to the researcher to teach for the whole semester was chosen. All the thirty-nine female students were from the preparatory year program of the university. Most of the students had their primary education at public schools where the Arabic Language was the medium of instruction, but English was taught as one of their subjects within the school curriculum. All the students in this sample were enrolled in the preparatory year's advanced level of English for General Purposes (EGP)course at Umm Al Qura University. The level for the course was determined based on their performance in an English placement test administered at the beginning of the year. The subjects ranged from 17 to 21 years of age.

\subsection{Research Instrument}

This study intended to extract students' information about their reading habits in L1 and L2. The sample provided information by answering the questions of an online questionnaire and semi-structured interviews regarding their reading habits in Arabic Language and English Language. For in-depth information, field notes from class-observations were also used. To assess their L2 proficiency, scores of formative assessments comprising of three quizzes and scores of summative assessments comprising of mid-semester exam and final exam were used to calculate the cumulative percentage.

\subsection{Research Procedures}

In the present study, data were collected in different stages. Firstly,field notesof continuous class observations were documented, then a questionnaire comprising of 30 questions was administered to collect the information about the reading habits of all the students. After that, each student was interviewed either individually or in a group to get indepth information about reading habits in L1 and L2.Finally, the percentage of each student was calculated using their formative and summative scores during the semester.

\subsection{Data Analysis}

The data collected from all the used methods were analyzed in two steps. Initially, the reading habits of the students were exploredby analysing the data obtained from the questionnaire, then the field notes and interviews were interpreted to get in-depth information about the reading habits of learners. After that, based on the analysis, students were divided into two groups. These groups were categorized based on their reading habits in the Arabic language and the English language respectively. Students in group A read and prefer to read for pleasure in the Arabic language, whereas students in group B read in Arabic language as well as in English for fun and other purposes. Then the percentage of all the formative and summative assessments done throughout the semester was calculated. Lastly, the percentage of both the groups was compared to know whether there is any relation between the reading habits in L1, L2 and the second language proficiency of the EFL learners. 


\section{4- Results and discussion}

In this section, the findings from all the collected data will be presented and discussed following the research questions posed in the study.

\subsection{Reading habits of students}

All the students usually read books in Arabic and English for academic purposes every day, indeed more of their reading for academic accomplishments has been done in the Arabic language. In the questionnaire, thirty questions were asked to explore their reading habits in L1 (the Arabic language) and in L2 (English language) in a pleasure reading context. The first item was concerned about their preference of language to read books and the results show that little less than half of the students $(46.1 \% \%)$ reported that they prefer to read books in Arabic and the other (54.8\%) prefer to read in Arabic as well as in English. There isn't any student who prefers to read only in the English language as shown in Figure 1.

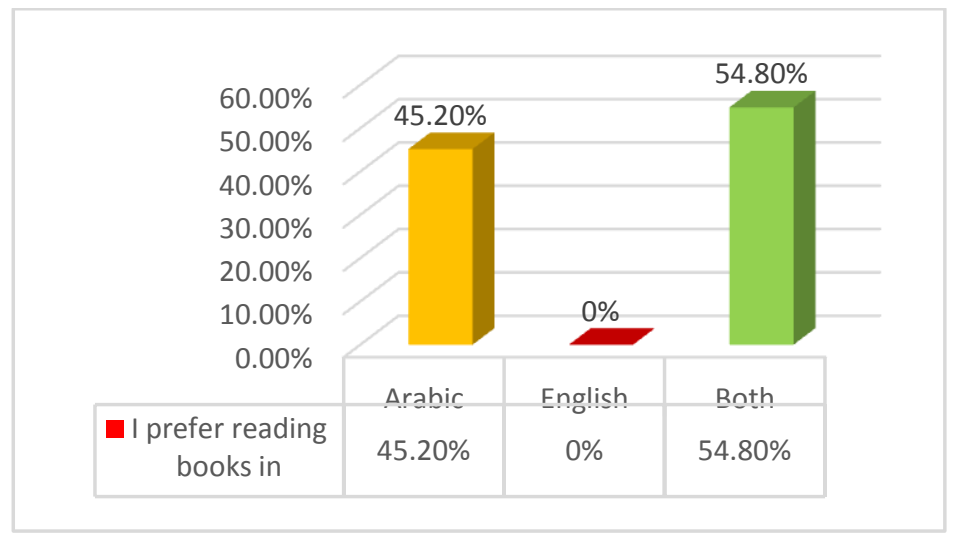

Figure 1: language preference for reading

To get information about attitude towards reading, their past experiences were also observed. Obviously, positive reading experiences develop a positive attitude towards reading which gradually helps language learners to become engaged readers. In their schools, learners used to read the maximum in the Arabic language. More than half of the learners (65.9\%) reported reading in L1and 34.1\% used to read in both the languages. On the contrary, in college, more than half of the students (61\%) read in both L1 and L2 and a very low number of learners (only 2.4\%) read in Arabic. This wide difference may be attributed to a sudden change in the education system from school to higher education. (see figure2).

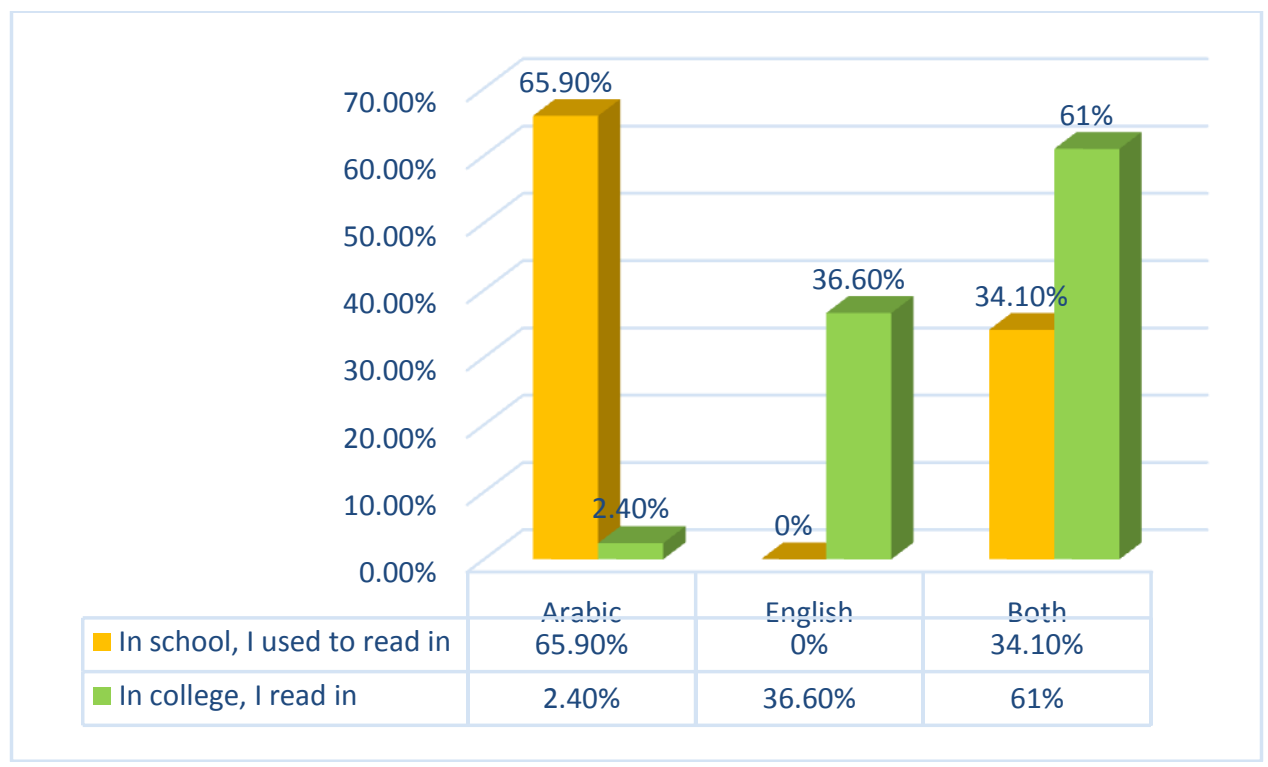

Figure 2: Preference in the past and present 
Moreover, when asked about enjoying reading in L1 at school, (19.5\% and 29.3\%) were strongly agreed and agreed respectively. More than one-third (39\%) of the students were neutral and 17\% didn't enjoy reading at all. The statistics indicate that the majority enjoyed reading in $\mathrm{L} 1$ at a young age. In comparison, almost $58.5 \%$ of learners enjoy reading in L1and L2 in college, but 41.5\% enjoy reading in the Arabic language only. Hence, the comparative analysis of the reported answers shows that there is a great change in the reading habits of learners over the period of time and learners found to be positively influenced by pleasure reading in L2 as presented in figure 3 .

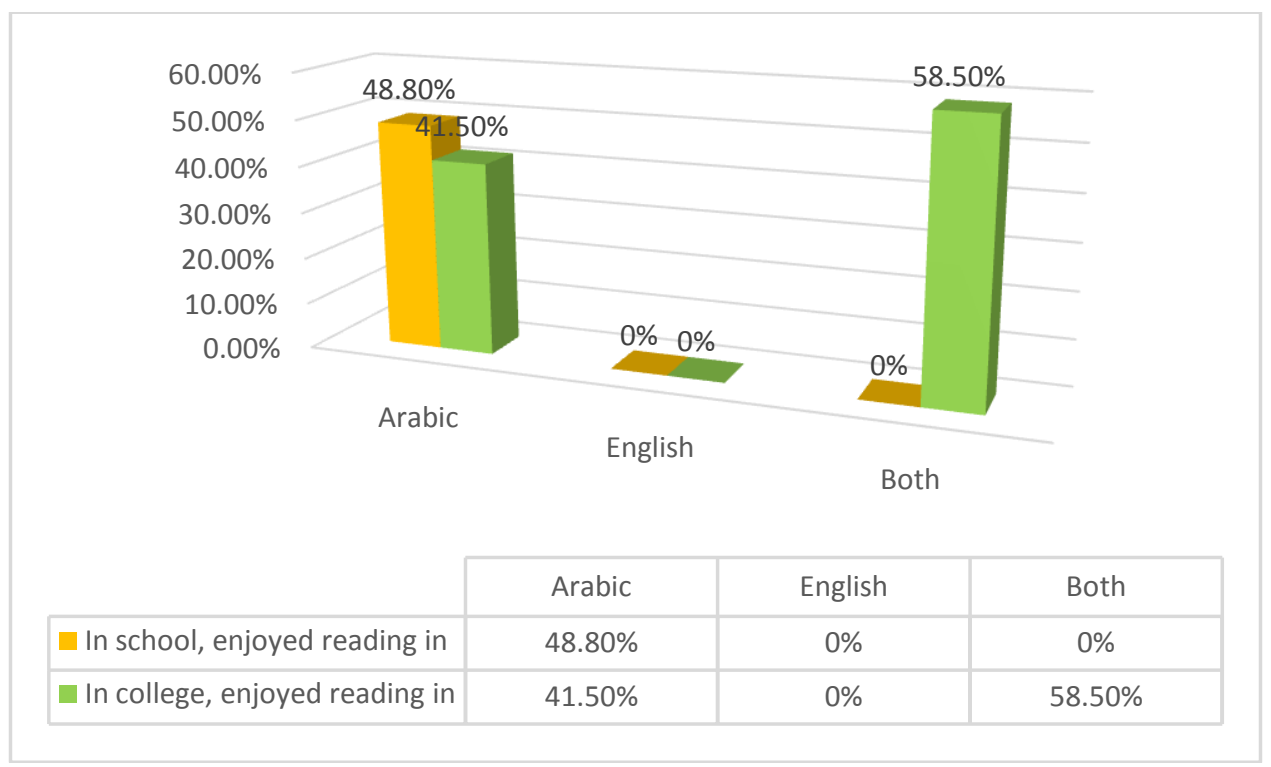

Figure 3: Reading habits in school and college

Another area of concern in today's social and cultural milieu is the declining trend of book culture. In this techno-savvy world, the young generation has been indulged more in net surfing rather than reading books. They prefer searching for information from the internet than books. In this regard, almost half of the students (51.2\%) agreed that they learn more from surfing the net than reading books, but one-fourth (24.4\%) either have a neutral view or disagree with it.

Maximum students (almost 70\%) disagree that they read only to find information, indicating students' good reading habits. Also, $76 \%$ of students have a collection of books at home points out that most students have a good reading culture at home. On the other hand, $48.8 \%$ of students don't borrow books for reading from libraries, $22.9 \%$ borrow books for reading whereas a considerable number i.e. $29.3 \%$ is neutral towards this aspect. So, lack of library culture is evident from the aforementioned statistic. (figure 4)

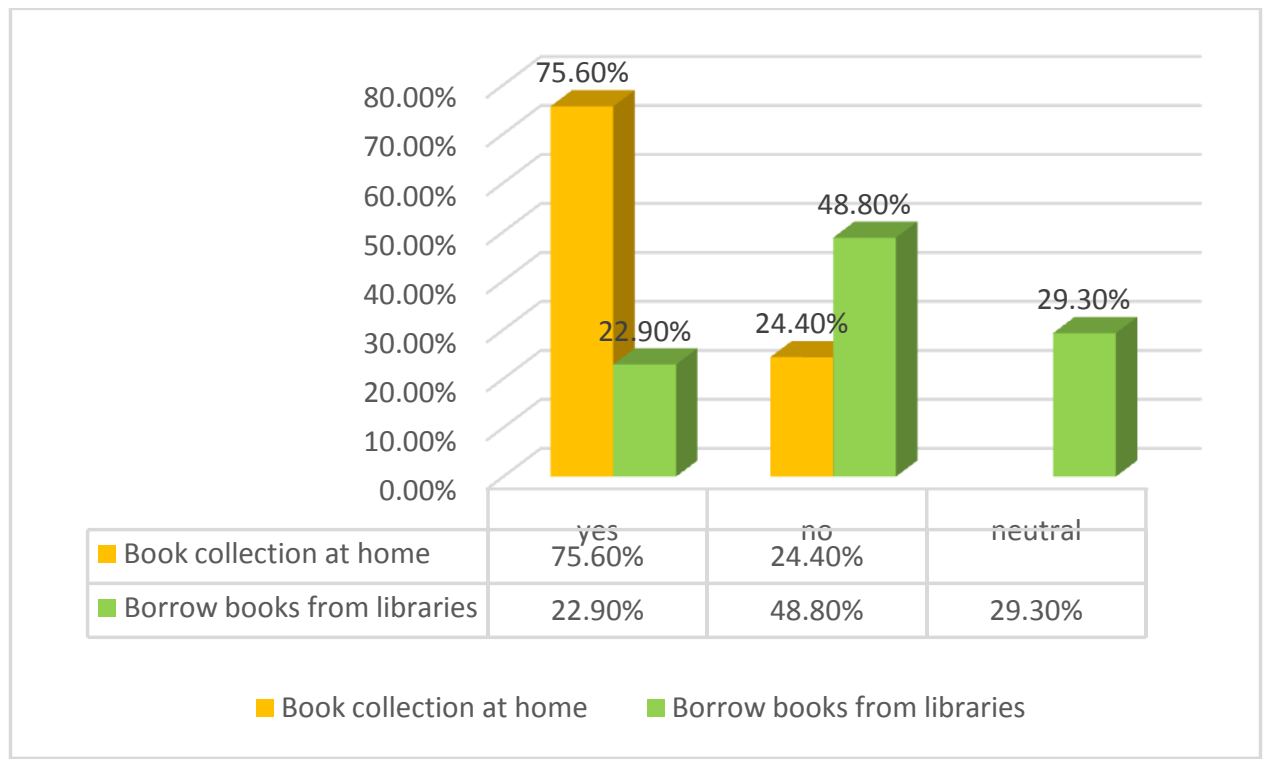

Figure 4: Reading culture 
It is important to point out that the majority of students are very well aware of the relevance of the English language for their academic and professional success. When students were asked that reading in English will be helpful in their careers, $56.1 \%$ of students are strongly agreed, $34.1 \%$ agreed and $9.8 \%$ are neutral. Hence, a big number i.e. $90.2 \%$ all together agree with the importance of L2 in their prospects. (figure 5)

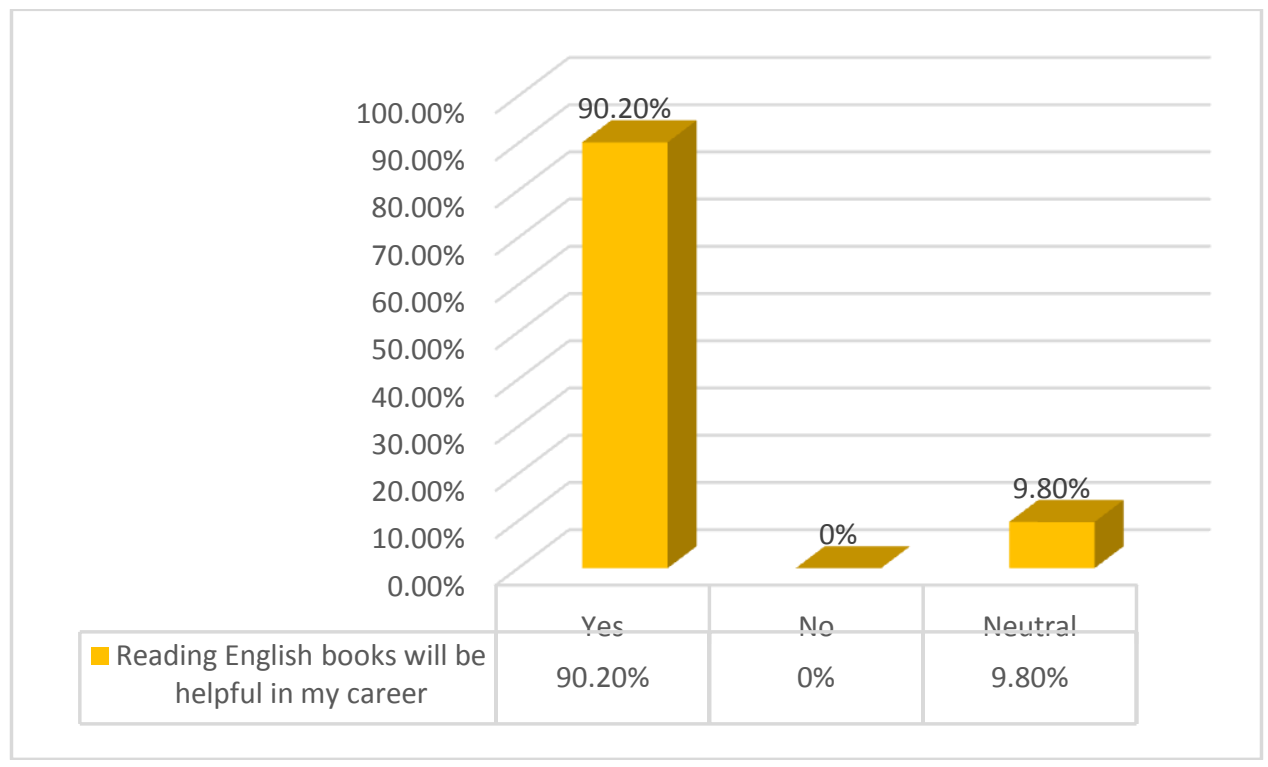

Figure 5: Importance of English reading in careers

The data defies the stereotypes that students who prefer to read in L1 may be less motivated to learn English. The motivational attitude of students L2 reading is clearly reflected when $53.7 \%$ of students strongly disagree, $39 \%$ disagree and $7.3 \%$ are neutral with the item stating that they don't want to read English texts after graduating from university. Further, $36.6 \%$ strongly agree and $53.7 \%$ agree that they want to master the skills of reading English, a negligible number of $2.4 \%$ disagreed with this view. The majority of students corresponding to $48.8 \%$ (strongly agreed) and $39 \%$ (agreed) have set up a goal to improve English language proficiency, whereas $2.4 \%$ of students do not have a goal to improve L2 proficiency. All the previous statistics are in a similar vein showing the motivated attitude of FL learners toward L2. Figure 6 shows that $82.9 \%$ of students admit that reading helps in language learning, only $4.9 \%$ disagree with it and $12.2 \%$ are neutral. (Figure 6)

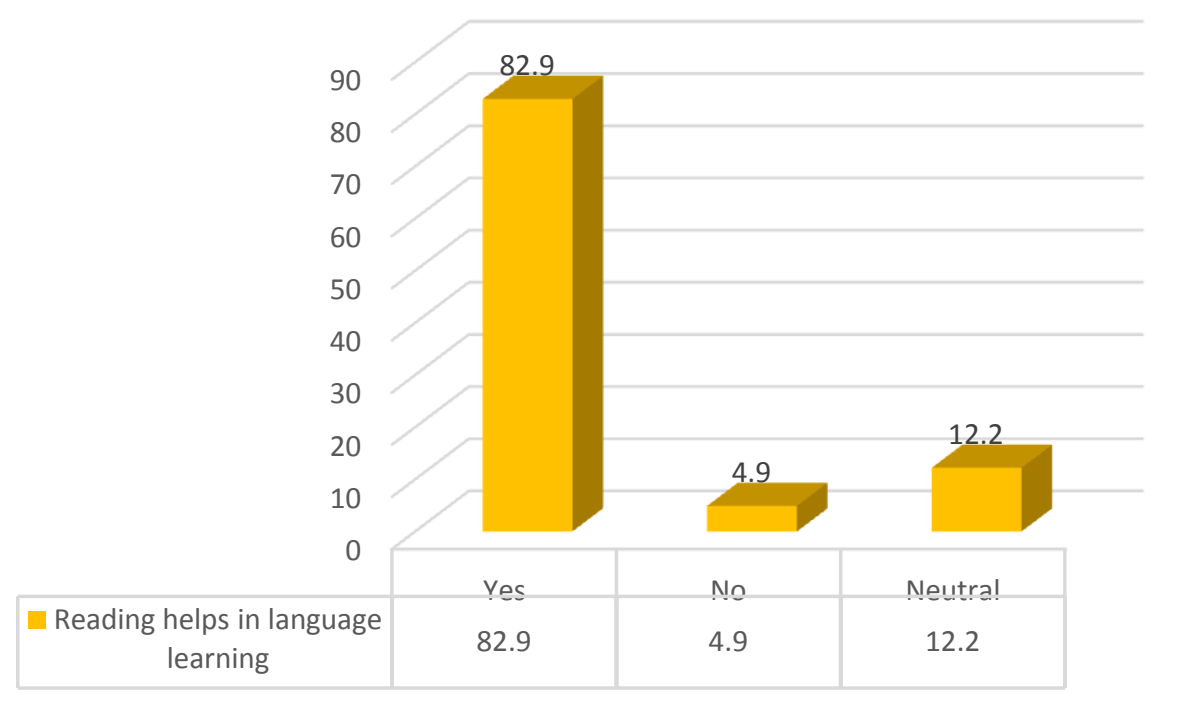

Figure 6: Reading helps in language learning 
Many studies have proved that FL learners encounter lots of difficulties in the process of learning to read. Indeed, such unpleasant reading experiences are one of the reasons for learners' reluctance to read. This may be the case with the sample of this study too. Majority students (48.8\%) agree and $4.9 \%$ strongly agree that they face difficulties in comprehending the meaning of words in reading English texts, contrarily, only $17.1 \%$ of learners disagree with difficulty level in $\mathrm{L} 2$ reading.

In-depth information from field observations and semi-structured interviews also manifested that most of the students were not motivated to read for pleasure either in L1 or L2 by their teachers at schools. At college, they seemed to be overloaded with projects and assignments of other subjects that they cannot manage enough time to read for pleasure. Obviously, the level of difficulty in L2 reading texts further discourages them to avoid L2 reading.

To sum up the above interpretation of data, the majority of students have good reading habits in L1 or both L1 and L2, in addition, they have a positive attitude towards L1 and L2 reading. Furthermore, they are motivated and are well aware of the importance of L2 language proficiency in their lives.

\subsection{Relation between reading habits and L2 proficiency}

To answer the second research question, inferential analysis has been done to find out the relationship between reading habits and L2 proficiency which is represented in a tabular form as shown in table 1. (table1)

\begin{tabular}{|l|l|l|l|}
\hline Group & Highest Score & Lowest Score & Mean \\
\hline A & $93.68 \%$ & $73.68 \%$ & $83.27 \%$ \\
\hline B & $93.15 \%$ & $72.10 \%$ & $84.43 \%$ \\
\hline
\end{tabular}

\section{Table1: Scores of group $A$ and $B$}

Based on their reading habits in L1 and L2, the learners were divided into two groups- group A and group B. The highest score in group A is $93.68 \%$ and group B is $93.15 \%$. Even though the learner from group A has more exposure in L1 through pleasure reading, she scored negligibly better than her counterpart from group B with a difference of $0.53 \%$. Another comparative analysis demonstrates a similar outcome as the lowest score in group A is $73.68 \%$ and group B is $72.10 \%$. The difference between the two scores is in the same vein i.e. the student from group A scored better than her counterpart from Group B with the $1.58 \%$ of margin. Table 1 and figure 7 illustrate the numerical analysis of the data. (figure 7)

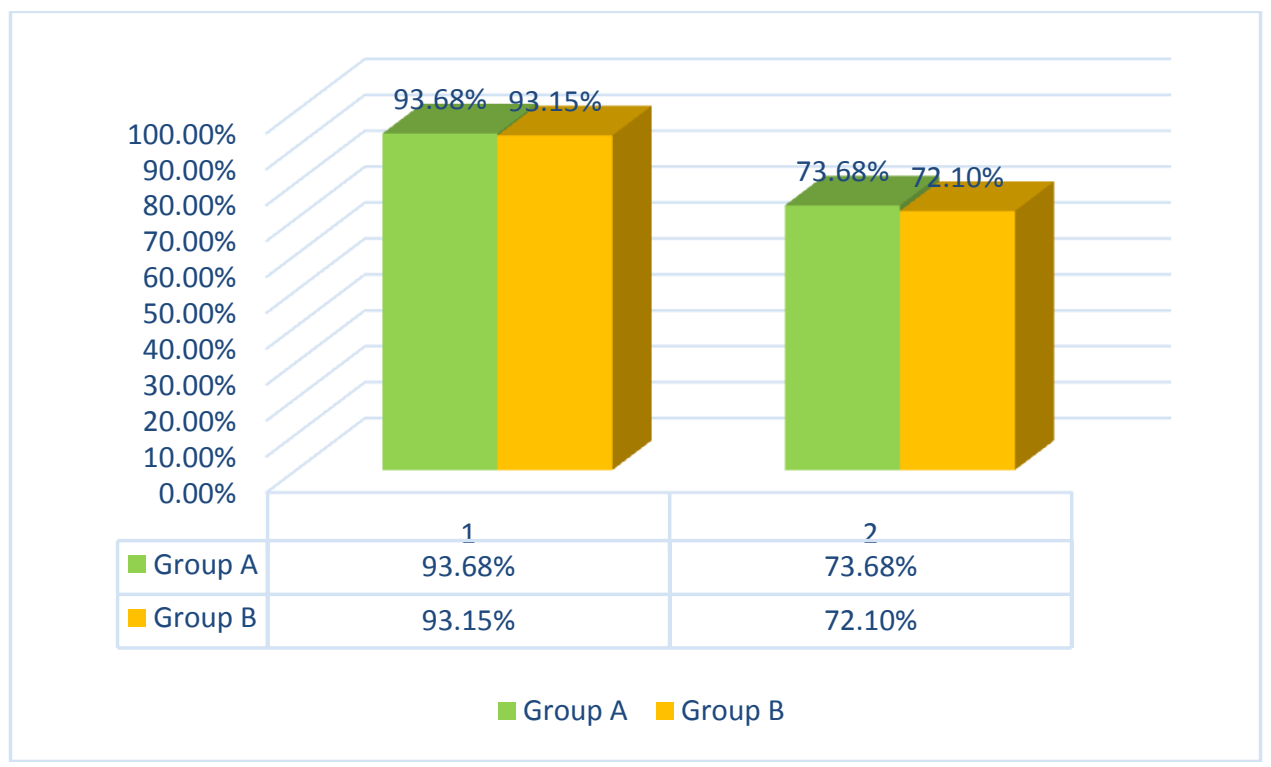

Figure 7: Highest and lowest score in both the groups

Further, the comparison of the L2 proficiency level of both groups was done by calculating mean of the scores. The results exemplify that the difference between the mean scores is not very considerable. The mean score of group A is $83.27 \%$ and that group B is $84.43 \%$, though in this regard group B outperformed slightly with $1.16 \%$ in contrast to individual performance with the difference of $0.53 \%$. (see figure 8 ) 


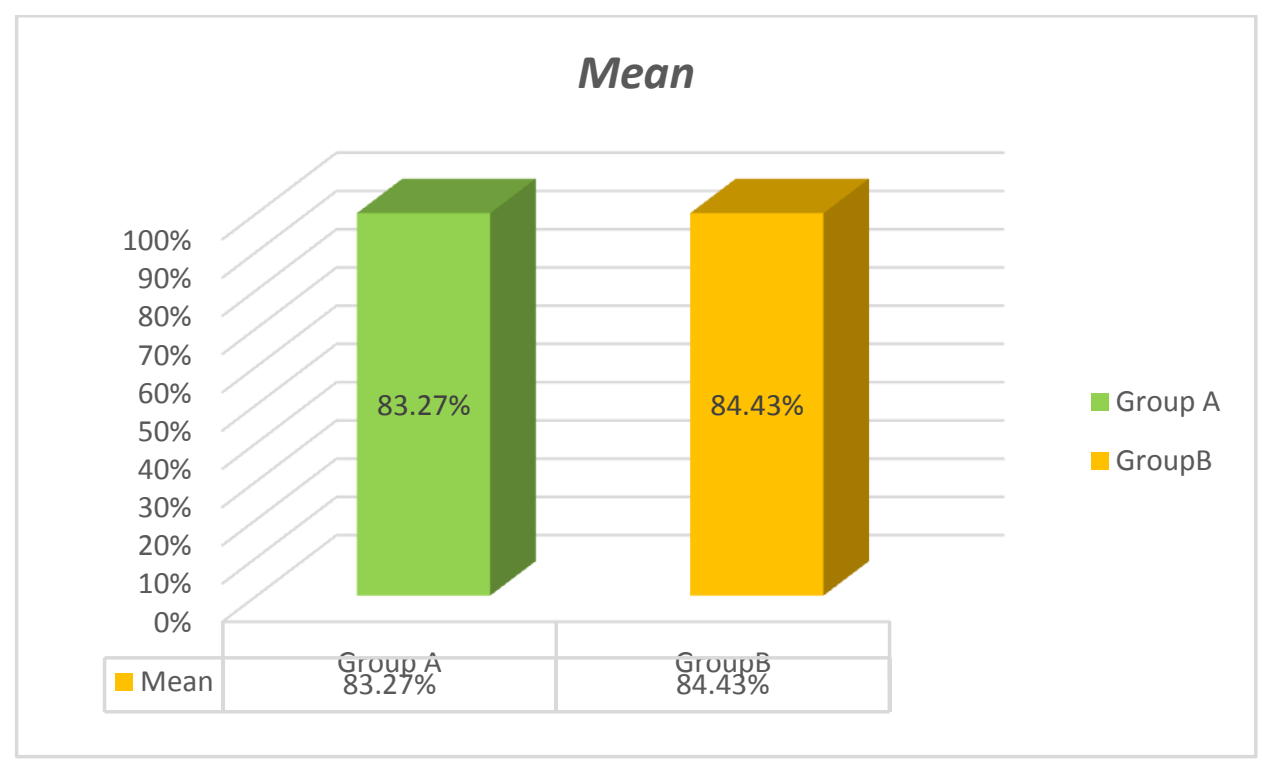

Figure 8: Mean score of both the groups

Therefore, all the above numerical presentations indicate that there isn't any noticeable relationship between L1 and L2 reading habits with the L2 language proficiency. The performance level of the students who have more exposure to L1 through pleasure reading is almost the same for the students who read in both the languages (Arabic and English) for pleasure and fun.

\section{5- Conclusion}

This study aimed to qualitatively and quantitatively explore the reading habits and their relation to the L2 proficiency level of Saudi EFL learners. To meet the purpose of understanding L1 and L2 reading habits, learners' attitudes towards L2 reading, motivational level and difficulty level in English were also observed. Perhaps, it is assumed that students who read more in L1 and avoid reading in L2 may have less ability to succeed in L2 exams. However, the findings contradict such assumptions since the cumulative percentage of both the groups are almost similar.

The correlation between the L1 and L2 reading habits and second language proficiency is negligible and the causes for it seem to lie in the students' affirmative attitudes toward the social value and educational status of English as also asserted by Al Qahtani (2016). Moreover, students' reluctance may be attributed to the difficulty level which they encounter while reading English texts. Also, the L2 proficiency of the learners who have less exposure to L2 should not be perceived as low performers in comparison to those who have more exposure to L2 pleasure reading. Hence, the study has pedagogical implications as it enables teachers to have insight into the reading habits, reading attitudes, and motivational factors that shape up the reading habits. Such information about the students' reading habits may help teachers to employ better measures in the EFL classes and that may lead to accomplishing learners' as well as teachers' goals.

\section{Limitations}

The sample size of the study was 39 female students who were non-randomly selected, thus the results may not be generalised on the population.

\section{Acknowledgment}

I would like to thank the students at Umm Al Qura University (UQU)who helped in collecting data for this study. Immense thanks go to the authorities at UQU for supporting and encouraging me during the study.

\section{References}

Al-Mansour, N. (2009). Bilingualism and the need for early EFL education in the Kingdom of Saudi Arabia. King Saud University Languages \& Translation Journal, 21, 1-12. 
Al-Mansour, N. S., \& Al-Shorman, R. E. A. (2011). The effect of teacher's storytelling aloudon the reading comprehension of Saudi elementary stage students. Journal of King Saud University, Languages and Translation, 23(2), 69- 76. [Online] Available: http://dx.doi.org/10.1016/j.jksult.2011.04.001

AL-Nifayee, A. M. (2010). The Effectiveness of the Instrumental Enrichment Approach on The Enhancement of Reading Comprehension Skills of Preparatory Stage Pupilswith English Language Learning Difficulties. (Master's thesis), Taif University, Saudi Arabia.

Al-Nujaidi, A. H. (2003). The relationship between vocabulary size, reading strategies, andreading comprehension of EFL learners in Saudi Arabia. Doctorate Thesis. Oklahoma State University.

Al- Qahtani, A. A. (2016). Why Do Saudi EFL Readers Exhibit Poor Reading Abilities? English Language and Literature Studies; Vol. 6, No. 1; [Online] Available:http://dx.doi.org/10.5539/ells.v6n1p1

Alderson, J. C. (1984). Reading in a foreign language: A reading problem or a languageproblem? In J. C. Alderson, \& A. H. Urquhart, Reading in a foreign language (pp. 1-24). London: Longman.

Carrell, P. L. (1991) Second Language Reading: Reading Ability or Language Proficiency?Applied Linguistics. 12. 59179.

Clarke, M. (1980). The short circuit hypothesis of ESL reading or when language competenceinterferes with reading performance. Modern Language Journal, 64, 203-209.

Cummins, J. (1979). Linguistic interdependence and educational development of bilingual children. Review of Educational Research, 49, 222-251.

Crystal, D. (2003). English as a global language. Cambridge University Press.

Crystal, D. (2010). The Cambridge encyclopedia of language. 3rd Edition, Cambridge: Cambridge University Press.

Day, R. (1998) Extensive Reading in the Second Language Classroom. Cambridge: Cambridge University Press.

Elley, W.B. \&Mangubhai, F. (1983) The impact of reading on second language learning.Reading Research Quarterly. Fall. pp.53-67

Goodman, K. (1967). Reading: A psycholinguistic guessing game. Journal of the Reading Specialist, 6, 126- 135, [Online] Available:http://dx.doi.org/10.1080/19388076709556976

Goodman, K., (1994). Reading, Writing, and Written Texts: A Transactional SociolinguisticView. In R.B. Ruddell,M.R. Ruddell,\& H. Singer (eds.), Theoretical models and processes of reading ( pp. 1093-1130). Newark, International Reading Association.

Hammerberg, D. D. (2004). Comprehension instruction for socio-culturally diverseclassrooms: A review of what we know. The Reading Teacher, 57(7): 2-12.

Hao, Y. \& Chi, R. (2013). The Positive Role of L1 in the Acquisition of a Second Language.Studies in Literature and Language, 7 (2), 45-48. [Online] Available:

http://www.cscanada.net/index.php/sll/article/view/j.sll.1923156320130702.H862

Ise, K.(2007) A Literature Review of the Effects of Reading on the Development of Skills in a Second Language.83-99 [Online] Available:(https://www.jiu.ac.jp/files/user/education/books/pdf/832-14.pdf

Krashen, S. 1993. The power of reading. Englewood, CO: Libraries Unlimited

Krashen, S. (2004). Free Voluntary reading: New Research, Applications, andControversies. Paper presented at the RELC Conference, Singapore, 2004. [Online] Available:

http://www.sdkrashen.com/articles/singapore/01.html/

Krashen, S.D. (2004).The Power of Reading: Insights from the Research. Portsmouth: Libraries Unlimited.

Liu, L. (2014) Language Proficiency, Reading Development, and Learning Context.

Frontiers: The Interdisciplinary Journal of Study Abroad, 14, 73-92. [Online]

Available:https://files.eric.ed.gov/fulltext/EJ1062130.pdf

Liu, F. (2010). Reading abilities and strategies: A short introduction. International EducationStudies, 3(3), 153-157.

[Online] Available:http://dx.doi.org/10.5539/ies.v3n3p153

Mourtaga, K. (2004). Investigating Writing Problems among Palestinian StudentsStudying English as a Foreign Language. Indiana: Author House.

Mourtaga, K. (2006). Some reading problems of Arab EFL students. Al-AqsaUniversity Journal. Al-Aqsa University, Gaza.

Nunan, D. (1991). Language Teaching Methodology: A Textbook for Teachers. HemelHempstead: Prentice Hall International.

Nunan, D. (1999). Second language teaching and learning. Boston, MA: Heinle\&Heinle.

Nuttall, C. (1996). Teaching Reading Skills in a foreign language. Oxford: Heinemann.

Park, G. (2013) Relations among L1 Reading, L2 Knowledge, and L2 Reading:

Revisiting the Threshold Hypothesis. English Language Teaching, 6, (12), 38-47.[Online] Available:

http://dx.doi.org/10.5539/elt.v6n12p38 
Qrqez, M. \& Rashid, R. A. (2017). Reading comprehension difficulties among EFL learners: The case of firstandsecondyear students at Yarmouk University in Jordan. Arab World English Journal, 8(3), 421-431.

Rodrigo, V., Greenberg, D. and Segal, D. (2014) 'Changes in reading habits by low literate adults through extensive reading'. Reading in a Foreign Language, 26 (1): 73-91.

Richards, J. C. \& Schmidt, R. (Eds.). (2002). Longman dictionary of language teaching and applied linguistics $\left(3^{\text {rd }}\right.$ ed.). London: Longman.

Schmidt, R. 2001. Attention. In Cognition and Second Language Instruction, P. Robinson (ed.), 3-32. Cambridge: CUP

Shang, H. (2011). Exploring the relationship between EFL proficiency level and reading strategy use. International Journal of Humanities and Social Science, 1(3), 18-27.

Smith, L. (2013). Higher Education in Saudi Arabia. New York, NY: Springer.

Taillefer, G. E. (1996) L2 Reading Ability: Further Insight into the Short-circuit Hypothesis.Modern Language Journal, 80(4), 461-477.

Tarulli, L. (2016) 'Do You Remember that Moment You, You Know, Became a Reader?'Reference\& User Services Quarterly, 55 (4): 270-272.

Yamashita, J. 2004. Reading attitudes in L1 and L2, and their influence on L2extensive reading. Reading in a Foreign Language, $7,1$.

Yamashita, J. (2013). Effects of Extensive Reading on reading attitudes in a foreign language. Reading in a Foreign Language, 25(2), 248. 